\title{
Ecos de la Declaración conciliar "Gravissimum Educationis momentum" a los 50 años de su publicación
}

\author{
P. CHICO GONZÁLEZ
}

SUMARIO: Declaración del Vaticano II sobre la educación como necesidad mundial de urgencia. Aparentemente fue texto de segunda categoría, pero intentó ser orientador de una nueva etapa eclesial: la etapa que supera la visión histórica de la educación como suplencia y como obra de misericordia; y de la etapa de la competencia de los centros cristianos como rivales de los públicos, seculares o estales. Refleja el deseo de resaltar la educación como obra de justicia y valora las entidades cristianas de educación, primaria, media o superior, como plataformas de presencia testimonial de la Iglesia en los servicios de formación humana de niños, jóvenes y adultos. Palabras clave: educación, derechos humanos, presencia cristiana, justicia.

ABSTRACT: This is the Vatican II Declaration on education as urgent global need. Apparently it was second-rate text, but tried to be guiding a new stage eclesial: a stage exceding historical vision of education as replacement and work or mercy, and the stage of competition as rival centers of Christian and public, secular or of the state. It reflect the desire of highlight education as work of justice and Christian values education, institutions, primary, secundary or higher, as platform token presence of the Church in human education service of children, youth and adults. Key words: Education, human rights, christian presence, justice.

Entre los 14 documentos emanados del Concilio Vaticano II hubo varios especialmente orientadores para los educadores, como fue la Constitución pastoral "Gaudium et spes", el Decretro "Optatam Totius" sobre 
la formación de los sacerdotes o el Decreto "Inter mirifica" sobre los medios modernos de comunicación social.

Pero el Concilio acogió bien la propuesta de las comisiones preparatorias de que hubiera un texto explícito sobre la educación y los centros escolares. Fue un documento interesante, pero no revolucionario, testimonial pero no directivo, manantial de sugerencias pero no de consignas normativas. Ello no quiere decir que no fuera clarificador y que luego resultara orientador en documentos posteriores, como fueron la Exhortación apostólica de Pablo VI sobre la evangelización (Evangelii Nuntiandi del 8 de diciembre de 1975) o la de Juan Pablo II sobre la catequesis (De Cathechesi Tradendae del 16 de octubre de 1979). Incluso impulsaría los cánones del Derecho canónico sobre las escuelas, como se advierte en el Código promulgado por Juan Pablo II el 25 enero de 1983, (cc 796 a 833 ), tanto en las partes relacionadas con la educación en general como en las normas sobre la catequesis y la educación religiosa (cc 793-795 y 773-780).

La Declaración conciliar sobre la educación, Gravissimum educationis momentum, fue la menos vibrante y transformadora de las tres declaraciones del Concilio, presentándose sólo como Declaración testimonial sobre la actitud de la Iglesia en relación a la formación humana. Las otras dos Declaraciones, la Dignitatis humanae, sobre la libertad religiosa, y la Nostra Aetate, sobre las relaciones con las religiones no cristianas, tuvieron el mérito de orientar a los cristianos en aspectos concretos, como la libertad religiosa ante el pluralismo social la una y sobre las relaciones con otras creencias y sociedades religiosas la otra.

Fueron estas otras Declaraciones documentos directivos en aspectos en los que había un desfase en los comportamientos de los católicos ante un mundo tan pluriforme y liberal, como el nacido después de la Segunda Guerra mundial. Acosado por un laicismo militante y desconcertado ante hechos masivos, como la explosión demográfica o la revolución tecnológica, ese mundo precisaba una orientación y consignas operativa y a ello tendieron las dos declaraciones. Pero la Declaración sobre educación fue más bien un apoyo laudatorio a lo que se venía haciendo en la Iglesia, salvo en dos o tres puntos particulares en que se resaltó el valor de las universidades católicas y la investigación.

La educación, de manera especial la escolarizada o formal, fue siempre un tema prioritario en las obras de los cristianos. Se catalogó durante siglos entre las obras de misericordia, como consta en los catecismos de la edad moderna, comenzando por los emanados del concilio de Trento 
(Catecismo Astete y Catecismo de Ripalda, no en el Romano de Trento, que solo las cita, Cfr Edición BAC. 1956 pg 186).

Con el tiempo se fue viendo que era más bien reclamo de justicia, que afecta a las personas y no las "obras" y se cambió la óptica en su valoración, que es lo que late en la Declaración Gravissimum educationis.

La encíclica Divini illius Magistri (Pío XI 31.11.1939) fue la "gran llamada a valorar la educación". Era todavía, al comenzar el Concilio Vaticano II, un centro básico de referencia educativa en los ámbitos católicos. Hoy nos sonreímos al leer esa Encíclica y la consideramos poco "progresiva" y un tanto difusa. Y es que nos vamos adaptando a la revolucionaria transformación habida en todo el mundo, sobre todo en los países occidentales, que mayoritariamente fueron cristianos en cultura, en tradiciones y lo que es estrictamente pedagógico.

Se esperaba del Concilio una renovación clarificadora, incluso revolucionaria, en criterios y en estrategias, conformes con el ambiente internacional que se respiraba en organismos como la UNESCO, la OMS, la UNICEF y se respiraba en estructuras católicas como la OIEC (Oficina Internacional de la Educación Católica) fundada en 1952. La Declaración universal de los derechos humanos de la ONU (del 10 de diciembre de 1948) o la formulación en la ONU de los Derechos del Niño (20 de noviembre de 1959), habían tenido mucha resonancia, sobre todo en Europa, donde el tema de los derechos se hizo más condicionante y exigente. Pero la Declaración conciliar no llenó tales expectativas. Fue más bien un refrendo muy convencional sobre la educación en general. Algunos periodistas tildaron el documento de rutinario y formalista, que es lo mismo que decir que el texto era "de obligado cumplimiento", rutinario y repetitivo, pero no interpelante de las conciencias al estilo de los otros documentos.

Algunos documentos conciliares, como la Constitución pastoral Gaudium Spes y el Decreto "Inter mirifica" sobre los medios de comunicación social, resultaron más admirables y con amplia resonancia mediática. En contraste, el texto de la Declaración sobre la educación pareció más bien de "apagado", ni normativo ni orientador, ante los conflictos generados por la nueva cultura tecnológica o por la explosión arrolladora de las corrientes secularistas que se iniciaban cuando en el Concilio se debatía el texto.

Con todo no es correcto exagerar el desfase o la aparente insuficiencia. Las discusiones y las aportaciones, que no fueron muchas (sólo 21 en el debate conciliar) al presentar el documento, resultaron tal vez más cla- 
rividentes que el mismo texto final consensuado. El debate, moderado y convencional, fue de los más tranquilos en el Concilio. Las tensiones se apagaron en la fase de preparación en las Comisiones, donde siguió un camino un tanto fatigoso, a juzgar por las diversas redacciones a las que hubo de someterse, para dar satisfacción a las pocas demandas que surgieron.

Resultó largo de consensuar porque algunos protagonistas del mismo querían algo más comprometedor para la Iglesia. Corrientes como la "desescolarizadora" en Norteamérica y la "pedagogía liberadora" de América del sur apenas si asomaron sus utopías en ninguna intervención. La impresión es que se contentaban con alabar lo que se hacía desde siempre. Al fin se optó por no excederse en planteamientos audaces, aunque se hizo lo posible para que no quedara corto en las pretensiones. Las discrepancias fueron muchas, no tanto en el estilo cuanto en los contenidos, que fueron quedando reflejados en esas múltiples redacciones (hasta ocho) motivadas por las disputas de comisión, pero no por discrepancias en lo poco que fue debatido en Asamblea general.

El documento resultante, modesto en su extensión, fue el segundo más breve de todos los documentos conciliares: 2.604 palabras en su redacción latina oficial. Era diez veces menor que el texto de la Gaudium et Spes, que tuvo 23.335 palabras. Y un poco mayor que el Decreto Inter Mirifica, el cual cuenta con 2.225 palabras.

A pesar de que a simple lectura parezca más literario que ideológico, se puede mirar como una confirmación conciliar de la tercera etapa de las escuelas cristianas en la Iglesia.

¿Qué significa hablar de tercera etapa? Que predominó la idea de "presencia", sobre la de "competencia" o la de "suplencia" en las estrategias docentes de la Iglesia cristiana.

Se puede recordar que hasta el siglo XVIII, la Iglesia se movió, en lo que a educación se refiere, en un nivel asistencial y con una actitud de suplencia. Ella suplió con abundancia lo que era incapaz de entender y hacer la sociedad civil, es decir, lo que fueron incapaces de valorar y realizar los poderes públicos (reinos, repúblicas, gobiernos, Estados) En esa etapa asistencial la Iglesia promocionó la educación y la escolarización como una obra de misericordia: "enseñar al que no sabe". La etapa primera, larga por tradicional, fue de "suplencia". La Iglesia hizo en Europa y en todos los ambientes mundiales a donde llegaron los misioneros europeos, una labor decisiva y primordial: educar e instruir, crear escuelas y promover maestros que enseñaran a leer y escribir. Los Estados nunca 
sintieron el deber de ofrecer la educación infantil y juvenil, en escuelas y en universidades.

También fueron las ideas conciliares una superación de la etapa posterior, la segunda, que se puede denominar como de la "competencia". En el siglo XIX y en parte del XX los centros de Iglesia, que surgieron a millares en todas las naciones, fueron "mejores" que los ofrecidos por las leyes generales de los Estados, que comenzaron a surgir después de que Napoleón Bonaparte dictara la norma imperial en 1804 para que todos los ciudadanos fueran a las escuelas y se instruyeran. Esas leyes generales, como soporte de la restauración y de la lucha contra la ignorancia, en todos los países fueron promoviendo la educación generalizada, pues obligaban a los poderes públicos a crear escuelas y sostener las labores docentes. Surgió una doble red de centros que se puso en funcionamiento y con frecuencia en "competencia" con la red sostenida y promovidas por las instituciones de Iglesia.

La calidad de las escuelas de Iglesia estuvo basada en la dedicación de los muchos "religiosos" masculinos y femeninos que vocacionalmente se dedicaron a instruir y a educar. La mayor sensibilidad religiosa de los promotores de esas escuelas garantizó la calidad, no sólo la confesionalidad, en los centros regidos por los institutos eclesiales. Y esa calidad resaltó, sobre todo en comparación a la acción de los "maestros seglares" en los centros públicos o estatales. En los unos la educación que se ofrecía era más selecta; y en los otros no era mala, pero inferior y más "proletaria", incluso escasa en recursos y en personas con vocación. Los profesores seglares eran más "laborales", bajo el carácter de funcionarios o de contratados por distintos organismos públicos. Y no podían superar las ventajas de los sostenidos por docentes más "consagrados" y desinteresados, como eran los religiosos o los profesores elegidos por ellos como complementarios

Pero desde mediados del siglo XX la educación empezó a tener el carácter de un "derecho público fundamental" en las legislaciones. En la Iglesia fue surgiendo la duda de si no era injusto defender una escuela de mayor calidad sólo por su rasgo confesional. Y se advertía que todos los hombres tienen el derecho a recibir igual educación. Se fue haciendo la sociedad más sensible a la "igualdad de oportunidades", a la libertad docente, al deber de una "educación básica igualitaria y gratuita" para todos los ciudadanos.

La Iglesia en muchos lugares se orientó a reconocer y reclamar el derecho igualitario de todos a recibir educación cada vez de más calidad. 
Y los hombres de Iglesia se fueron dando cuenta de que la confesionalidad, el tener centros de ideario cristiano y evangélico, es diferente de la calidad, del tener centros y realizar labores educadoras de alto valor en el orden de la instrucción y sobre todo en la formación de las personas.

La Declaración del Concilio no anunció explícitamente este tránsito como mejor que lo anterior; pero vino a ser un himno a la formación moral y religiosa y un motor para defender la igualdad de todo los hombres en derechos educativos. Proclamó que todos los hombres deben contar con posibilidades de educación de calidad, pues ante la educación, como ante el aire, el agua y el sol, todos los seres humanos tienen los mismos derechos naturales.

Por eso el documento conciliar se hace eco del deber y de la necesidad de que le Iglesia se haga presente en todo lo relativo de la educación, porque ello tiene mucho que ver con la realidad humana y espiritual de sus miembros. En el comienzo del texto se afirmaba: "Cada vez se realizan más esfuerzos para promover la obra de la educación y se consignan en documentos públicos los derechos primarios de los hombres, especialmente de los niños y de los padres, con respecto a la educación.......] Por eso también a la Iglesia corresponde atender a toda la vida del hombre, incluso a la material, en cuanto está unida a la vida celeste, con el fin de cumplir el mandamiento recibido de su divino Fundador, a saber anunciar a todos los hombres al mismo Cristo; por eso le toca también a ella en parte contribuir al progreso y a la extensión de la educación" (introducción).

Después se multiplican las expresiones del compromiso eclesial en educación. "Este Concilio exhorta a los hijos de la Iglesia a que presten con generosidad su ayuda en todo el campo de la educación, para que pueda llegar cuanto antes a todos los rincones de la tierra" $\left(\mathrm{n}^{\circ} 1\right)$.. Y recuerda "a los pastores de almas su gravísima obligación de proveer a todos los fieles de una educación cristiana y sobre todo a los jóvenes que son la esperanza de la Iglesia" $\left(\mathrm{n}^{\circ} 2\right)$.

Se recuerda que "la presencia de la Iglesia en la tarea de la enseñanza se manifiesta sobre todo por la escuela católica, la cual busca, no menos que las demás escuelas, los fines culturales y la formación humana de la juventud. Pero su nota distintiva es "crear ambiente comunitario animado por el espiritu evangélico de libertad y de caridad..., de modo que sea iluminado por la fe el conocimientos que los alumnos van adquiriendo del mundo, de la vida y del hombre" $\left(\mathrm{n}^{\circ} 8\right)$.

Laten más o menos explícitas en el texto aprobado por el Concilio las diversas afirmaciones en torno a la hermosura de la vocación educadora 
y las alabanzas a las escuelas de todo tipo, resaltando los derechos de los padres a buscar para sus hijos lo mejor en este terreno y defendiendo la voluntad de la Iglesia de estar presente en el ámbito escolar y cultural, no para suplir ni para competir (primera y segunda etapa) sino para cumplir el mandato misional de su divino Fundador: dar testimonio de la verdad salvadora.

El texto recordó algo a los padres cristianos: la conveniencia de buscar preferentemente los centros de ideario cristiano, entendiendo por tales, no sólo los que ofrecen clases de información y de formación religiosa, sino los que viven, en las actividades y en los programas, el espíritu y las consignas del Evangelio, sólo posible si se cuenta con personas que dan testimonio de su fe y de su vida cristiana ${ }^{1}$.

\section{Etapas de la redacción del documento}

Es interesante recordar y resaltar que no fue fácil el pacto entre los que trabajaron en las comisiones conciliares y que se ocuparon y preocuparon de esta Declaración. Era difícil consensuar un texto que respondiera al deseo de lograr una postura clarificadora de lo que significa la educación cristiana hoy. El ideal era común a todos: coincidir en los caminos por donde discurrirá mañana la educación cristiana, según el criterio de "aggiornamento" (Juan XXIII) o de "être a la page" (Pablo VI) que parecía ser objetivo general del Concilio.

Pero las ópticas eran diferentes: unos se centraba en la educación formal que se da en las escuelas de diversos niveles, de modo que tenían su mente el valor las escuelas de la Iglesia. Otros pensaban que los ámbitos no académicos son incluso más importantes que las instituciones sistemática y regulares. Pruebas de la dificultad de avenirse las dos posturas fueron las ocho veces en que se cambió el contenido del esquema inicial. El esquema final resultante de las disputas era muy diferente del que se presentó a los conciliares por primera vez.

El conseguido se discutió muy rápidamente en la comisión el 12 y 13 de junio de 1964. Fue aceptado con cierta facilidad y rapidez, pues había

\footnotetext{
${ }^{1}$ Las ideas del Vaticano II han multiplicado muchas publicaciones y estudios, incluso medio siglo después del Concilio. Cfr. Hace 50 años hubo un concilio. Significado del Vaticano II, Victorio Codina Mur [Monografía] Madrid Ed. Justicia y Paz. 2012. Los resultados fueron comentados luego por diversos escritos y publicaciones, como el trabajo "La educación según el concilio Vaticano II”. José María Valladolid. Salamanca. Sígueme 1967.
} 
otros temas más candentes y urgentes (el esquema 13, el de la libertad religiosa, por ejemplo). Luego se presentó en la Asamblea general del mismo mes y las 21 intervenciones se "ventilaron" en tres sesiones. Para llegar a ello hubo un camino largo que nos interesa conocer. Fueron siete veces las que lo rehicieron los 25 miembros de Comisión conciliar antes de llegar a la Asamblea General ${ }^{2}$.

\section{- Antes de iniciarse el Concilio}

El esquema primero había sido redactado por una comisión antepreparatoria, llamada de "Estudios y seminarios", creada, entre otras, el 5 de abril de 1960. Dispuso de unas 1900 respuestas recibidas cuando se pidieron a todas las diócesis del mundo temas e ideas para el Concilio (Carta del Cardenal Tardini del 18 de junio de 1959). Respuestas sobre el campo de la educación y seminarios fueron varios centenares. Pero 81 propuestas se centraron en la escuela, de manera especial en la escuela cristiana. Fueron esas propuestas el material de arranque y las obligaron a separar el tema de los Seminarios para otra comisión creada al efecto.

El texto logrado se envió en Junio de 1962 a los Obispos del mundo, con el título de "De scholis catholicis"3.

- Primera etapa conciliar. 11 octubre a 8 diciembre de 1962

Se designó la Comisión de Educación y escuelas católicas. Como en las Demás comisiones, fueron 25 los miembros, 16 elegidos por el Concilio y 9 designados por el Papa. El texto preparado por la comisión preparatoria fue traspasado a la comisión conciliar, presidida de nuevo por el Cardenal Pizzardo. Redactado de nuevo fue aprobado con algunos retoques por esta comisión. Eran 34 páginas de sentencias laudatorias sobre las escuelas católicas de diversos niveles y variadas características. Su título era "De scholis christianis et studiis". Tenía el aval satisfactorio de expertos consultores. Pero tuvo que esperar medio año casi para poder ser

2 "Cuando fue anunciado el Concilio no había en la Iglesia problemas grandes de fe, de comunión o de disciplina. La situación general era pacífica. En muchas parte la vida de la Iglesia era fecunda. No estuvo, pues, el concilio condicionado ni en su temática ni en sus actitudes por serias provocaciones". Confr. la hermosa Introducción de D. Ricardo Blázquez a la edición Concilio Vaticano II: Constituciones, Decretos y Declaraciones. Madrid. Ed. Católica. BAC, 1993. pgs XVI a XXXVII.

${ }^{3} \mathrm{Cfr}$ "La educación en el concilio Vaticano II en el magisterio de Juan Pablo II. Susana M. Marañón Muñoz. Universidad de Deusto, Microforma 1995. 
remitido a los Obispos, labor que correspondía a la Comisión central del Concilio y al Secretariado del mismo.

- Mientras tanto se volvió a discutir el documento en comisión y se rehizo el contenido. En marzo de 1963 quedó determinado el texto con pretensión de ser, ahora sí, el definitivo, aunque no con unanimidad de opiniones. Unos querían resaltar la importancia eclesial de las escuelas cristianas. Otros demandaban mayor amplitud de miras y pensaban que no era suficiente condensar y responder a las 81 propuestas anteconciliares recibidas. Se necesitaba resaltar los elementos de formación de los medios de comunicación social.

Las previsiones y las ideas generalizadas en el Concilio, como quedaría reflejado en el otro documento conciliar, el "Inter mirifica", eran propensas a ampliar la óptica de las reflexiones y de las consignas eclesiales con una perspectiva pastoral y no disciplinar ni ideológica, según la voluntad del Papa convocante del Concilio, Juan XXIII.

- A pesar de las disensiones, en mayo de 1963 se envió por correo a los Padres el primer esquema conciliar del documento. Era un texto, el cuarto, muy breve, con una introducción y tres partes: una general sobre la educación y dos sobre las escuelas católicas y las universidades de la Iglesia. Los conciliares hicieron observaciones y la comisión trató de adaptarse a ellas. Así se logró el quinto texto, o mejor la quinta redacción del texto.

- La Comisión central mientras tanto volvió a examinar el texto los días 12 y 13 de junio de 1963 y reclamó que se ampliará la perspectiva, de modo que el panorama ideológico y pedagógico adquiriera más "altura", más dimensión universal y más referencia a los cambios culturales del mundo. Con disgusto de los redactores se aceptaron las observaciones, o mejor los criterios y las exigencias, y se decidió renovar el discutido texto por otro más agudo, a fin de ser presentado a discusión y aprobación. Prácticamente se hizo nueva redacción.

- Segunda etapa conciliar: 29 septiembre a 4 de diciembre de 1963

- Ninguna variación hubo en este tiempo de sesiones y estudios de los otros documentos. La Comisión sobre la Educación tuvo algunos encuentros intersectoriales, pero dio por bueno lo que tenia presentado y difundido. Siguió sin captar lo que había ya en la sociedad de educación no escolarizada o no formal y el eco en un mundo en el que los medios de 
P. CHICO

comunicación desbordaban los libros de texto escolar y los programas didácticos de las escuelas, asignaturas y materias diversas. Esperaba sólo la oportunidad para ser contrastado en el Concilio.

- La comisión Central del Concilio el 23 de enero de 1964 determinó que el texto adquiriera forma de "Declaración", no de Decreto, y se redujera a fórmulas votables para acelerar las sesiones conciliares. Salieron 17 proposiciones breves y el título quedó en "De Scholis catolicis". Fue el quinto texto. Se enviaron de nuevo por correo a los conciliares y se recibieron diversas reacciones que, ante la brevedad del texto, no fueron positivas. Se mostraron múltiples discrepancias y se vio el texto poco adaptado a los cambios del mundo.

- Entonces la Comisión recogió en mayo de 1964 las opiniones de los diversos Padres y amplió el texto con nuevas aportaciones. Así se llegó con nueva perspectiva (sexto texto), aunque de igual trasfondo. Pero se modificó el título proponiendo el de "Declaratio de educatione christiana".

- Se lograba una dimensión ampliada a toda la educación humana, con referencia a la ofrecida por las instituciones cristianas, con ordenadas alusiones a las escuelas católicas, a las universidades de inspiración cristiana y a las necesidades de la educación como derecho natural de todos los hombres, cristianos o no. Se aludía a otros tipos de escuelas diferentes de las católicas y se ensalzaba la labor de todos los educadores que preparan a los hombres a integrarse en la cultura nueva que aparece y en la realización como personas libres en un mundo en cambio.

- Tercera etapa conciliar: 4 septiembre a 21 noviembre de 1964

- La oportunidad de la discusión en Asamblea General llegó en esta tercera etapa y "se despachó" de forma fugaz en las jornadas del 17 al 19 de noviembre de 1964. El Obispo belga Mns. Daem fue el ponente cuando se presentó ante los Padres conciliares y supo ofrecer con atractivo lo que es la educación en general como derecho natural y lo que representa en particular la cristiana como labor prioritaria en el mundo y en la Iglesia.

- El texto pasó un tanto distraído a pesar de las 21 intervenciones interesantes pero rápidas, entre las que destacaron las del Cardenal Spellman de América, del Obispo Elchinger de Estrasburgo, del Arzobispo de Indonesia, Mons. Schneiders y del de Dalat, en Vietnam, Mons. 
Nguyen Van Hien. Sobre todo el Obispo auxiliar de Caracas, Mons. Henríquez, tuvo la intervención más amplia y razonada. El Arzobispo Mons. Guyon de Rennes solicitó una comisión postconciliar para estudiar un tema tan necesario como la educación cristiana, ya que, dijo, "no había tiempo de hacerlo en el Concilio y sería un fraude a la juventud cristiana, que pide en todo el mundo una buena clarificación de la postura de la Iglesia sobre las escuelas y los problemas educativos"4.

- La fugacidad de las aportaciones ofrecidas tiene su explicación comprensible. El Concilio tenía en ese período temas más conflictivos y complejos: el de la libertad religiosa era el principal y dividía con cierta agresividad los ánimos. Por eso se "despachó" el tema de educación de forma rápida y sin entrar a fondo en lo propuesto por la Comisión. De hecho la orientación era muy restrictiva: un proemio y siete capítulos sobre principios generales acerca de la acción educadora de las instituciones escolares, aunque se aludiera a los derechos de la familia y de la Iglesia; se citaba la necesidad moderna de instrucción amplia, se reclamaba atención a los derechos y deberes de los maestros, se recordaba la necesidad de promover la escuela confesional católica.

El texto, sometido a votación en tres sesiones, se analizó primero por partes (17 a 19 de noviembre de 1964) y obtuvo 1.879 votos a favor, 419 "non placet" y uno nulo. Los discrepantes se apoyaron o en su brevedad o en la impresión de que no se valoraba suficientemente la educación en el contexto de las exigencias de los nuevos tiempos. Quedó pendiente el mejorarlo con las intervenciones de los Padres y el someterlo a la votación definitiva.

- Con los aportes de esas intervenciones se configuró el texto final, el octavo. La Comisión tomó en serio las rectificaciones y complementos, puesto que quedaba la votación final. Las intervenciones de esos $21 \mathrm{~Pa}$ dres en esos días conciliares y las aportaciones escritas de diversos consultores conciliares obligaron a la revisión final del texto presentado y votado.

\footnotetext{
${ }^{4}$ La citada comisión quedó identificada con la Congregación romana para la educación católica, la cual publicó diversos documentos en los años posteriores. Así salió La Escuela católica, el 19 de abril de 1977. El laico católico, testigo de la fe en la Escuela, 15 octubre 1982; La Sapientia Christiana de Juan Pablo IUI, el 29 de abril de 1979, sobre la Facultades eclesiásticas y la Constitución Ex corde Ecclesiae, sobre las Universidades de la Iglesia, del mismo Papa en el 15 de julio de 1990.
} 
- El texto se preparó entre el 23 y el 30 de marzo de 1965 por parte de una subcomisión de expertos, en la que figuraron nombres como los de Mons. Daem, como presidente, y figuras como Hoffet, Massi, Onclin, Suárez, Bednarski y M. Sauvage, todos ellos representantes de entidades católicas significativas. (Mons. Daem lo era de la OIEC) ${ }^{5}$. Del 26 al 3 de mayo la comisión recogió el texto de los expertos y lo presentó al aula conciliar el 13 de octubre de ese año.

- Este texto iba estructurado en esta octava redacción en forma de una introducción sobre la importancia de la educación y en una cadena de 11 reflexiones, no muy originales, pero serias y bien argumentadas. Eran un tanto generales: 1) los fines de la educación en clave cristiana;2) la disposición de la Iglesia a colaborar con los pueblos y las diversas culturas para educar a todos los hombres: 3 ) la acogida de los diversos medios en la educación; 4) la importancia de la escuela y el derecho de los padres a poder elegir; 5) la necesidad de cooperar con las estructuras civiles de la sociedad; 6) la necesidad de discernir en la educación moral y religiosa con respeto a las conciencias; 7) el valor y la originalidad de las escuelas católicas; 8) la aceptación de la diversidad escuelas católicas; 9) el valor de de las facultades y universidades católicas; 10) la urgencia de renovar las facultades de ciencias sagradas; 11) y la conveniencia de la coordinación en los temas educacionales.

- Cuarta etapa conciliar. 14 de septiembre a 8 de diciembre de 1965

- Así corregido (textus emendatus se llamó), fue sometido a votación orientadora el 13 de octubre de 1965 y en esta ocasión obtuvo 1912 votos a favor, 183 en contra y 1 voto nulo. Mons. Daem afirmó que era un texto general, para dar principios y que más tarde comisiones al efecto dispondrían de consignas más concretas y operativas, labor que quedaba para la Santa Sede y sería posterior al Concilio. El ambiente era de compromiso, pues se quería acelerar todo para dar por terminado el Concilio según decisión del Papa. Por eso no se registraron casi reacciones, al menos en la

5 Referencias sobre las opiniones se pueden encontrar en reportajes al estilo de "Diario del concilio" de Henri Fresquet (enviado de Le Monde) Madrid Ed. Nova Terra 1967 o de "Un periodista en el Concilio". J. L. MARTín Descalzo. Madrid. Ed. PPC 1965 (4 vol). También en monografías como "Breve Historia del concilio Vaticano II" de J. MorALES MARÍN. Madrid. Rialp 2012. Y “El Concilio ecuménico Vaticano II. Contrapunto para su Historia. A. Marchetto. Madrid Ed. Cultural y Espiritual. 2008. 
forma solemne de las intervenciones en el aula. Tampoco las hubo con escritos o peticiones registradas.

- Cuando se pasó a la votación global definitiva, con algunas correcciones hechas y con sus 2.604 palabras en la versión latina, se logró una votación de 2.290 votos "placet" y sólo 35 votos non placet". Fue la votación tenida el 28 de octubre de 1965. Y fue el texto que promulgó Pablo VI en esa misma sesión solemne de octubre ${ }^{6}$.

\section{Los valores de esta Declaración}

La Declaración, tan laboriosamente conseguida, pero tan poco conflictiva en ideas, no pretendió ser más que una acción testimonial y orientadora de la educación en un mundo tan diverso en sistemas, corrientes y alternativas, como el que nacía a mediados del siglo XX. Reflejaba sobre todo el ámbito pastoral de los movimientos y de los centros de educación inspirados por la Iglesia.

No iba sólo para los católicos, sino para todos los hombres de buena voluntad, pues se trataba de decir al mundo que la Iglesia tomaba muy en serio la formación del hombre, no sólo la religiosa, sino la de todos los valores humanos que hacen la libertad, la dignidad y abren a la responsabilidad?.

No pretendió ser un "documento internacional" de orientación pedagógica. Sólo deseó ser un recordatorio del significado eclesial de la cultu-

6 Incluso ni el mismo Papa lo citó en su discurso de clausura al terminar el concilio, fuera de la referencia hecha a "todos los documentos finales" presentados en la sesiones conciliares. Sí hubo referencias globales en el mensaje final del Concilio a los hombres en la clausura del Concilio. En la parte que leyó el Cardenal Léger decía. "Un saludo para vosotros, los buscadores de la verdad, a vosotros los hombres de pensamiento y de ciencia... Nuestra marcha en estos cuatro años ha sido buscar la verdad... Vuestro camino es nuestro camino... Continuad buscando e investigando y recordad las palabra de vuestro amigo S. Agustín: "Busquemos con el deseo de encontrar y encontremos con el deseo de seguir buscando".

Y el Cardenal Agagianian, en las palabras dirigidas a los jóvenes les decía, al final del mensaje: "A vosotros los jóvenes de uno y otro sexo del mundo entero, el Concilio quiere dirigir el último mensaje: Sois vosotros los que vais a coger la antorcha de manos de vuestros mayores para vivir en un mundo que pasa las más gigantescas trasformaciones de la historia. Sois vosotros los que, recogiendo las enseñanzas de vuestros padres y maestros, vais a formar la sociedad del mañana: os salvaréis o perecéis con ella".

7 H. FresQuet. Op. cit. pg. 827 y ss. 
ra y una pista operativa para los católicos, pero también para los no cristianos, o al menos para los cristianos no católicos, como reconocieron algunos de los observadores ortodoxos o de otras confesiones. Por eso no tuvo una mirada catequética, sino un reconocimiento del valor social y moral de la acción educadora.

En el mismo texto se reconoce que la pretensión es "declarar algunos principios fundamentales sobre la educación cristiana y sobre las escuelas"... y que "después serán desarrollados por una comisión especial y aplicados por las diversas conferencias episcopales" (introd.) Posee pues una intención de "recordar", más que de renovar las líneas básicas de la formación humana y menos las estructuras pedagógicas para que los cristianos tengan conciencia del valor de la educación humana.

Los valores más destacados del documento, en el contexto ambicioso de todo el Concilio, pueden quedar condensados en los siguientes aportes destinados a los más responsables de la educación en el mundo actual.

1. La Iglesia católica reconoce el valor primordial de la educación del hombre, quiere aportar su visión propia sobre esta necesidad y reclama sus derechos como sociedad humana que también es, para promover los derechos de todos los hombres en este terreno. Alaba a los que se dedican a la noble tarea de educar y también invita a que haya muchos educadores cristianos que puedan aportar al mundo de las escuela y de la cultura los valores elevados que ella quiere promover en el mundo. Se resalta por ello en la Declaración la necesidad de la educación en la etapa juvenil de manera particular. Y se reclama la "constante formación de los adultos, más fácil y urgente en la circunstancias actuales... porque todos deben participar en la vida social, incluso económica y política... y en los maravillosos progresos de la técnica y de la investigación científica, en los medios nuevos de comunicación social"... porque la Iglesia debe atender a toda la vida del hombre, incluso material" ( $\mathrm{n}^{\circ} 1$ y 2 ).

Se insiste en que la educación, lo mismo que la vida y la libertad, es un derecho humano radical, más allá de la raza, del sexo, de las mismas circunstancias sociales o económicas de la personas. $\left(n^{\circ} 1\right)$. Los cristianos deben colaborar en las tareas educadoras de modo que resulten un beneficio para todos los hombres "por igual" y para que la educación no sea una causa o un factor de desajustes sociales. La educación no es un privilegio, sino una necesidad.

2. La igualdad, por lo tanto, inquieta al Concilio. Se preocupa por la educación específicamente cristiana, pero no menos su atención se orien- 
ta a la de todos los hombres. Reconoce que es la familia la primera educadora y la que debe exigir el respeto de las demás instancias sociales a su derechos y deberes.

Pero recuerda la importancia primordial de la escuela y sobre todo resalta la acción de los profesionales de esa labor humana. Ensalza la vocación de los docentes. "Hermosa es y de suma trascendencia la vocación de todos los que, ayudando a los padres en el cumplimiento de su deber y en nombre de la comunidad humana, desempeñan la función de educar en las escuelas. Esta vocación requieres dotes especiales de alma y corazón, una preparación diligentísima y una continua prontitud para adaptarse y renovarse" $\left(\mathrm{n}^{\circ} 5\right)$.

3. Atención especial presta la Declaración a la educación moral y espiritual en las escuelas de todo tipo, y de forma preferente en las escuelas católicas ( $\mathrm{n}^{\circ} \mathrm{s} 7.8$ y 9). Pero hay que entender que la Iglesia debe ejercer su ministerio educador en toda la vida de los creyentes, no sólo en el contexto escolar. Por eso la Declaración, que comenzó centrada en las "escuelas católicas", se fue ampliando en sus miras a lo largo de sus diversas redacciones y variaciones y trató al final de dar criterios básicos sobre todo tipo de educación y sobre el abanico poliédrico de los diversos centros donde se recibe este don de la educación en general.

En una intervención conciliar de Mons. Henríquez, obispo auxiliar de Caracas, el 19 de noviembre de 1964, se daban las razones de por qué los primeros esquemas presentados para configurar esta declaración se consideraron insuficientes al centrar su atención en la escuela católica y no abrirse a muchos más ámbitos. Decía este obispo conciliar:

"No toda la educación cristiana se debe hacer depender de las escuelas católicas... La Iglesia tiene obligación de educar cristianamente a todos los bautizados y no únicamente a los alumnos de escuelas católicas. Las escuelas católicas no son un fin en sí mismas sino un medio. No olvidemos que el número de niños y jóvenes católicos que van a las escuelas no confesionales aumentará en el futuro. $Y$ es un hecho que muy a menudo la Iglesia está ausente de las escuelas del Estado, ya que se considera una competencia el entrar en ellas. No obstante la Iglesia tiene el deber de estar presente y dar testimonio de Cristo en todas partes.

En nombre de ciento doce obispos concluyo:

- Procuremos promover las vocaciones de profesores que enseñan en las escuelas del Estado. Y no veamos todo en función de la escuela, sino pensemos que la escuela no es un fin sino un medio para lograr la educa- 
ción. Otros medios hoy invaden el mundo, como son los diversos cauces de comunicación social (prensa, radio, televisión, etc)

- Reservemos a los sacerdotes para la evangelización propiamente dicha y pongamos a los laicos como profesores de nuestras escuelas.

- Busquemos, no tanto la cantidad, sino la calidad [evangélica] de nuestras escuelas" (cf. $\mathrm{n}^{\circ} 7$ ).

Después de intervenciones de varios obispos en este sentido, el esquema tomó otra orientación y el texto terminó ampliando sus miras hacia la educación como fuente de valores humanos amplios y no sólo como recurso para la cultura y la evangelización. Por eso recuerda el Documento conciliar, con discreta reserva y moderación de términos, que en muchos países se han encontrado dificultades para ejercer el derecho a la educación según las preferencias de la familia. Insiste en la demanda de libertad, sobre todo después de las polémicas surgidas en el aula conciliar sobre libertad religiosa, tema que resultó ser el más conflictivo del Concilio.

4. Se reclama en el texto, además del respeto a los padres, el debido a la misma Iglesia por parte de los poderes públicos en todos los países de la tierra. Pues la Iglesia quiere ser testigo del mensaje evangélico y no institución competitiva con otras instancias sociales como son el Estado y la misma sociedad que puede generar en su seno multitud de alternativas educadoras.

El documento al final dejó muy clara su intención de orientar la labor educadora. Pero también dejó muy claro la justificación de que la Iglesia quiere tener libertad en las escuelas propias de los católicos, que deben servir de modelos de humanismo, pluralismo y apertura para todas las escuelas en las que se forman los niños y los jóvenes. "Este sagrado Concilio proclama el derecho de la Iglesia a establecer y dirigir libremente escuelas de cualquier grado y orden, derecho declarado ya en muchos documentos del Magisterio eclesial, recordando al mismo tiempo que el ejercicio de ese derecho contribuye en gran manera a la libertad de la conciencia, a la protección de los derechos de los padres y al progreso de la misma cultura" ( $\left.\mathrm{n}^{\circ} 8\right)$.

5. La segunda parte del documento analizaba el derecho a tener "universidades y facultades" propias por parte de la Iglesia. Y se preocupa, no sólo por las Universidades promovidas por instituciones de Iglesia, sino por todas las demás, sean públicas o privadas, reclamando la posibilidad de hacerse presente en todas las estructuras sociales, preferentemente en 
las destinadas a los jóvenes. La razón es sencilla: "La suerte de la sociedad y de la misma Iglesia está íntimamente conectada con el aprovechamiento de los jóvenes dedicados a los estudios superiores. Por eso los pastores de la Iglesia no sólo han de preocuparse de la vida espiritual de los alumnos que frecuentan las Universidades católicas, sino que han de ser solicitos con todos los demás" (nº).

La Iglesia tuvo desde los primeros tiempos de su Historia milenaria una atención preferente a todos los ámbitos culturales de naturaleza superior, que luego se llamarían Estudios Generales y más tarde Universidades. En ellos se gestó la cultura superior, que terminó siempre iluminando la sociedad. No es cierto que fueron las "madrazas" de las mezquitas, con su potente influjo social en Oriente y Occidente, las que inspiraron los estudios generales de las catedrales. Cinco siglos antes de Mahoma se multiplicaron las inquietudes por la cultura de altura. Basta recordar las figuras de S. Justino, de Tertuliano, de Orígenes, de S Agustín, de S. Basilio y de S. Benito para intuir lo que la Iglesia pensó siempre de los centros superiores, de las Universidades y de la formación en los seminarios de las diversas diócesis, al menos desde los decretos del concilio de Trento al respecto.

Es normal que el documento, por lo tanto, reclamara una revisión de las universidades promovidas en todos los países del mundo por la Iglesia y que reclamara el interés de que los miembros cristianos ejerzan su labor en los centros no católicos. El texto dice: "Puesto que la suerte de la sociedad y de la misma Iglesia está intimamente conectada con el aprovechamiento de los jóvenes dedicados a los estudios Superiores, los pastores de la Iglesia no sólo han de preocuparse de la vida espiritual de los alumnos que frecuentan las Universidades católicas, sino que, solícitos de la formación espiritual de todos sus hijos, con las consultas oportunas entre los Obispos, han de procurar también que en las Universidades no católicas existan residencias y centros universitarios católicos, en los que sacerdotes, religiosos y seglares, bien preparados y cuidadosamente elegidos, presten ayuda permanente espiritual e intelectual a la juventud universitaria. A los jóvenes de mayor ingenio, tanto de las Universidades católicas como de las demás, que ofrezcan aptitudes para la enseñanza y para la investigación, hay que prepararlos esmeradamente e incorporarlos a la enseñanza $\left(\mathrm{n}^{\circ} 10 \mathrm{y} 11\right)$. 
Es interesante releer 50 años después las ideas y las sentencias de esta Declaración sobre la educación cristiana y contrastar la resonancia que tuvo en su momento y compararla con la que puede tener hoy. A mediados del siglo XX media humanidad, la dominada por el comunismo, era objeto de observación temerosa por la otra media. "El comunismo que impera en gran parte de la humanidad, constituye uno de los signos más evidentes de los tiempos. Si no hablamos de él, ¿cómo nos juzgará la Historia" decía Mons. Bollati, arzobispo de Rosario, Argentina el 24 de octubre de $1964^{8}$.

Ha pasado medio siglo y han variado las ópticas sociales y los criterios de la Iglesia. Entonces se leyeron las conclusiones conciliares en este terreno y en aquel momento y se vieron como un reclamo de libertad terriblemente amenazada. Eran momentos de represión en la media Europa oriental y en prácticamente toda Asia. Hoy la libertad ha aumentado, al menos en muchos países. Entonces Europa estaba saliendo todavía de la pobreza sembrada por una Guerra mundial que llenó los campos de ruinas y los corazones de amargura.

Leer este texto ante el muro de Berlín y en una sociedad en la que el analfabetismo afectaba a más de la mitad de la humanidad, que no llegaba a los cuatro mil millones de habitantes, era una cosa. Leerlo hoy cuando el tal muro no existe, en Alemania claro, y cuando la guerra en Europa es un recuerdo y al llegar la humanidad a los siete mil millones de habitantes, es algo muy diferente.

Al recordar el valor de la educación como cauce de la libertad y como emblema de vanguardia en la promoción de los derechos humanos, la Iglesia hacía entontes un servicio gigantesco a la humanidad. Hoy sigue en la brecha.

Cierto es que los principios son perdurables y las realidades sociales son pasajeras. Hoy nos parece pobre la Declaración. Entonces, sobre todo en el mundo de la cristiandad, pareció más rica. Hasta qué cierto punto fue iluminadora en los grandes torbellinos de cultura, de la tecnología y de la comunicación y de liberalismo ético y laicismo ideológico, sigue siendo difícil de cuantificar a medio siglo de distancia. Hay una resonancia que impresiona. Han pasado cincuenta años y se sigue hablando del Concilio Vaticano II como si fuera muy reciente. Se olvidan las encíclicas de los papas, se olvidan los congresos, los documentos internacionales envejecen y hasta los atropellos de la Historia como son las guerras pasan.

8 H. FresQuet. Op. cit. pg. 831. 
Pero los documentos del Concilio Vaticano II se siguen citando con vigor juvenil.

Por eso es bueno recordar el gran principio de la libertad en la educación y el gran desafío de la necesidad de la cultura que esta Declaración promocionó y sigue recordando con vigor incomparable $\left(\mathrm{n}^{\circ} 8\right)$.

El deber de la educación fue una gran afirmación que la Iglesia contribuyó a difundir. Acaso sea la mejor prueba el reclamo de que la Declaración hizo en su pórtico como documento. "Corresponde a la Iglesia, no sólo el ser reconocida también como sociedad humana capaz de educar, sino, sobre todo, porque tiene el deber de anunciar a todos los hombres el camino de la salvación, de comunicar a los creyentes la vida de Cristo y de ayudarles con preocupación constante para que puedan alcanzar la plenitud de esta vida. La Iglesia, como Madre, está obligada a dar a sus hijos una educación que llene toda su vida del espíritu de Cristo y al mismo tiempo ofrece a todos los hombres su colaboración para que se asegure el bien de la sociedad terrena y la construcción de un mundo que debe configurarse de manera más humana" (n³).

Aunque parezca, y acaso sea verdad, que esta Declaración Gravissimum Educationis Momentum fue poco discutida en el aula conciliar, y tal vez quede en el lector una impresión desenfocada de lo que el Concilio supuso en todos los aspectos tratados en la magna Asamblea, es preciso terminar estas breve ideas elevando un homenaje de gratitud a todos los que hicieron posible aquella grandiosa obra, que fue el gran acontecimiento del Vaticano II, el más grande de los veinte que se han celebrado en la milenaria historia de la Iglesia 9 .

Y podemos encontrar una correcta impresión en las palabras de un testigo de los que más trabajaron en el secreto y en la eficacia en la organización del acontecimiento. Mons. Pericles Felici, secretario general del Concilio, decía en una conferencia al poco tiempo de la clausura conciliar:

«Con la experiencia adquirida en estos años, puedo afirmar que la acción del Espíritu Santo se ha hecho sentir en este Concilio, mientras que con segura fe me atrevo a predecir que otras y mayores manifestaciones de la acción del Espíritu Santo llegaremos a ver en los años venideros. El Concilio ha quedado, en cuanto obra humana, contenida en decenas de volúmenes impresos, en millares de opúsculos, con los esquemas de los

${ }^{9}$ Muchas de las ideas está sugeridas o refrendadas por los textos y conferencias de "Concilio Vaticano II. 40 años después. IX Jornadas Agustinianas, celebradas en Madrid los días 11 y 12 de marzo de 2006". Editorial Agustiniana. Madrid 2006. 
decretos y de las constituciones reelaborados muchas veces, en kilómetros de cinta magnetofónica con las intervenciones de los padres conciliares, en la estadística y en los archivos de la Secretaría, en todo el aparato externo de organización técnica y administrativa, en las frecuentes y amplias informaciones emanadas de la oficina de prensa.

Un millar casi de personas, provenientes de todas las naciones y dotadas de las cualidades y de la experiencia más diversa, han colaborado en las comisiones preparatorias para elaborar el ingente material de estudio que debía ser examinado y discutido en el Concilio. A continuación, cerca de dos mil quinientos padres, en sesiones de diez semanas de duración cada una de las etapas, previo el estudio de los peritos, han ponderado atentamente cada frase y cada palabra de los esquemas presentados a la discusión conciliar. Trabajo de la inteligencia y de la voluntad humanas verdaderamente inmenso, que servirá entre otras cosas para esclarecer la doctrina y para la revisión y el aggiornanento de la disciplina eclesiástica.

Ciertamente, en este inmenso cuadro hay también sombras, lagunas, incertidumbres, contrastes, aspectos negativos. También esto es obra humana, que demuestra los límites de la inteligencia y de la naturaleza.

Pero debo también afirmar, con toda la fuerza de la verdad, que las luces han sido, más allá de todo posible parangón, más numerosas y más intensas que las sombras, y que las cualidades han superado a los defectos"10.

Y evidentemente también esto puede decirse de nuestra Declaración sobre la educación cristiana, cuyo recuerdo se nos viene a la memoria 50 años después de que se elaborara, se discutiera y se publicara por la Iglesia. Podemos resaltar su humildad y su grandeza: su humildad porque fue de los textos más sencillos del Concilio; su grandeza, porque fue refrendado por 2.290 obispos del mundo y porque sólo 35 no se enteraron del todo de lo que decía en ella, que de haberse enterado, claro que la hubiera apoyado con su "placet".

10 Pericles FeLICI (Cardenal Secretario del Concilio). El largo camino del Concilio. Madrid, Ediciones Palabra. 1967, pg. 292. 